\title{
Metal Sektöründe 5x5 Matris ve Fine-Kinney Yöntemi ile Risk Değerlendirmesi*
}

\author{
Risk Assessment with 5x5 Matrix and Fine-Kinney Method in Metal Industry
}

Aygül AKER (iD , Tijen Över ÖZçELiK (iD

\begin{abstract}
ÖZET
İş sağlığı ve güvenliği konusu tüm dünyada olduğu gibi ülkemizdeki çalışma hayatı için de en önemli sorunlardan birisi olarak karşımıza çıkmaktadır. Yapılan istatistiklere göre, ülkemizde yaklaşık her 5 dakikada bir iş kazası meydana gelmekte, bu kazalar sonucunda her gün en az 2 çalışanımız hayatını kaybetmekte ve iş göremez şekilde sakat kalmaktadır. Metal sektörünün ülkemizde aktif bir imalat sektörü oluşu sebebiyle bu alanda kaza oranları ciddi oranda bir artış göstermekte olup, bu sektörde meydana gelen kazaların büyük çoğunluğu ölümle veya iş göremezlikle sonuçlanmaktadır. Bu nedenle firmalarda işverenlerin ve çalışanların bu sorunla ilgili bilinçlendirilmesi gerekmektedir. Risk değerlendirmesi, işyerindeki risklerin önceden belirlenerek gerekli önlemlerin zamanında alınması ve bu şekilde kayıpların büyük ölçüde azaltılmasını sağlamaktadır. Bu çalışmada metal imalatı yapan bir firmada belirlenen riskler analiz edilerek risk değerlendirme yöntemleri yardımıyla risk değerlendirmesi yapılmıștır. İș sağlığı ve güvenliği çalışmalarında uygulama kolaylığı açısından da sıkça tercih edilen $5 x 5$ Matris ve Fine-Kinney yöntemi ile karşılaştırmalar yapılarak iki yöntemin sonuçları değerlendirilmiştir. Karşılaştırma sonucuna göre Fine-Kinney yöntemi 5x5 matris yöntemine kıyasla daha hassas sonuçlar verdiği görülmüştür.
\end{abstract}

Anahtar Kelimeler: İş Sağlığı ve Güvenliği, Risk Değerlendirmesi, Fine-Kinney Yöntemi, 5x5 Matris Yöntemi, Metal Sektörü

\section{ABSTRACT}

The issue of occupational health and safety is one of the most important problems for the working life in our country as well as in the whole world. According to statistics, approximately every 5 minutes in our country, an accident occurs, as a result of these accidents, every day at least 2 employees die and are disfigured as a work disability. Since the metal sector is an active manufacturing sector in our country, the accident rates in this area show a significant increase and most of the accidents in this sector result in death or incapacity to work. Therefore, employers and employees should be informed about this problem. With the risk assessment, it is ensured that the risks in the workplace are determined in advance and necessary measures are taken in a timely manner and thus losses are greatly reduced. In this study, the risks determined in a metal manufacturing company were analyzed and risk assessment was performed with the help of risk assessment methods. Comparisons were made with 5x5 Matrix and Fine-Kinney method which are frequently preferred in terms of ease of application in occupational health and safety studies and the results of two methods were evaluated. According to comparison results, Fine-Kinney method was found to give more sensitive results than $5 \times 5$ matrix method.

Keywords: Risk Assessment, Occupational Health and Safety, Fine Kinney Method, 5x5 Matrix Method, Metal Industry

Aygül AKER I aygulsavas@hotmail.com

Sakarya Üniversitesi, Fen Bilimleri Enstitüsü, Yüksek Lisans Öğrencisi, 54187, Sakarya, Türkiye

Sakarya University, Institute of Natural Sciences, Graduate Student, 54187, Sakarya, Turkey

Tijen Över ÖzçELik | tover@sakarya.edu.tr

Sakarya Üniversitesi, Mühendislik Fakültesi, Endüstri Mühendisliği Bölümü, 54187, Sakarya, Türkiye

Sakarya University, Faculty of Engineering Department of Industrial Engineering, 54187, Sakarya, Turkey

Received/Geliş Tarihi : 08.10.2019

Accepted/Kabul Tarihi: 28.05.2020

(*) Bu çalışma Dr.Öğr.Üyesi Tijen Över ÖzÇELiK danışmanlığında Aygül AKER tarafindan 2019 tarihinde tamamlanan “iş̧ Sağlığı ve Güvenliğinde 5x5 Matris ve Fine-Kinney Yöntemi ile Risk Değerlendirme ve Metal Sektöründe Uygulanması” başlıklı ve 611917 tez no'lu yüksek lisans tezinden türetilmiştir. 


\section{GİRIŞ}

İşs sağlığı ve güvenliğinde temel amaç; çalışma yaşamında çalışanların sağlığına zarar verebilecek hususların önceden belirlenerek gereken önlemlerin alınması, çalışanların rahat ve güvenli bir ortamda çalısmalarının sağlanması, bedensel, ruhsal ve sosyal yönden tam iyilik halinin sağlanmasıdır [1]. Mesleki risklerin değerlendirilmesinde, iş sağl1ğı ve güvenliği bakımından çalışma ortamının ve çalışanların sağlık ve güvenliğini sağlama ve sürdürme amacıyla risk değerlendirmesi yapmanın önemi büyüktür. Risk değerlendirmesi iş kazaları ve meslek hastalıklarının neden olduğu kayıpların azaltılabilmesi için belirlenen ciddi düzeydeki risklerle ilgili düzeltici-önleyici faaliyetleri başlatabilmenin bilimsel yoludur [2]. Avrupa Komisyonunun yayımladığ rehberde, risk değerlendirmesi "İşyerindeki bir tehlikenin ortaya çıkması durumundan doğan, çalışanların sağlık ve güvenlikleri açısından risklerin değerlendirilmesi işlemidir” olarak tanımlanmıştır [3].

Kamu ve özel olmak üzere tüm işyerlerini kapsayan 6331 Sayılı İş Sağglı̆ı ve Güvenliği Kanunu, tehlikelerin ortaya çıkarılarak bu tehlikelerin sebep olabileceği risklere karşı önlem alınması gerektiğini vurgulamaktadır. Bunları yapabilmek ise, ciddi düzeyde yapılmış, gerçek anlamda uygulamaya konulmuş ve gerektiğinde revize edilmiş bir risk değerlendirmesi uygulaması ile mümkündür. Bu aşamada risk yönetimi kavramı, kazaların önlenmesi için sistematik ve gerçekçi bir çatı kurulmasını sağlar. Şekil 1'de görülen risk yönetim prosesi, tehlikelerin belirlenmesi, risklerin analizi ve değerlendirilmesi, önlemlerin belirlenerek yerine getirilmesi, inceleme, izleme, haberleşme adımlarının sistematik olarak uygulamasından oluşmaktadır.

Risk değerlendirmesi yapılmayan işletmelerde, çalışanları bekleyen tehlikeler ve riskler bilinmediğinden, iş kazası ve meslek hastalıklarının yaşanmasına ortam hazırlamış
Şekil 1. Risk yönetim prosesi

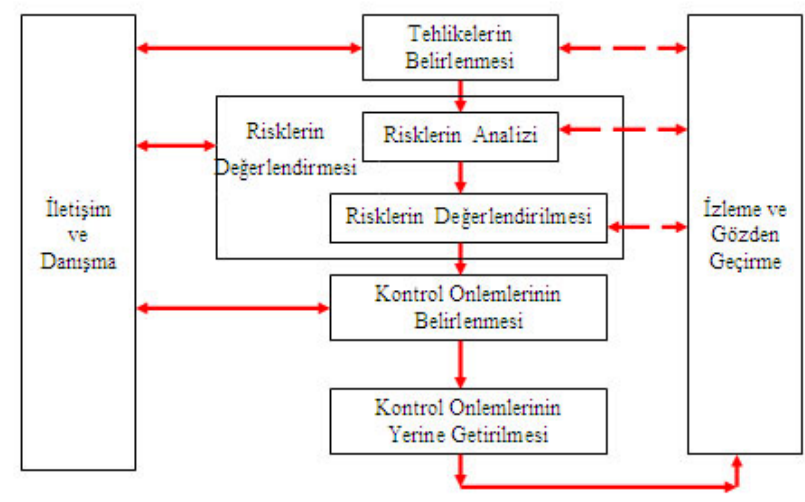

olunmaktadır [4]. 20.06.2012 tarihinde yürürlüğe giren 6331 sayılı İş Sağlığı ve Güvenliği Kanunu’nda belirtildiği üzere işveren, iş sağlığı ve güvenliği yönünden risk değerlendirmesi yapmakla yükümlüdür [5]. İşverenin en önemli yükümlülüklerden biri olan risk değerlendirmesi ile ilgili tüm işletmeleri kapsayan, İş Sağlığı ve Güvenliği Risk Değerlendirmesi Yönetmeliği, 29.12.2012 tarih ve 28512 sayılı Resmi Gazetede yayımlanarak yürürlüğe girmiştir [6].

Metal sanayi Türkiye'de tüm sanayi kolları içinde gerek ekonomik büyüklüğü, gerek istihdam sahası gerekse stratejik önemi açısından en önemli konumdadır. Bu büyük metal sanayinin içinde hayatımızın vazgeçilmezlerini oluşturan demir-çelik, otomotiv, yedek parça, beyaz eşya, savunma sanayi gibi sektörler bulunmaktadır [7]. Ancak bu duruma paralel olarak metal sektörü hem ülkemizde hem de dünyada çalışma koşulları bakımından en riskli sektörlerin başında gelmektedir. Toz, gürültü, sıcaklık, ışın, radyasyon gibi dikkat edilmesi gereken önemli riskler barındıran metal sektörü, son ylllarda ülkemizde meydana gelen iş kazaları açısından da ilk sıralarda yer almaktadır. Tablo 1'de SGK 2016 yll istatistiklerinden hareketle Makine Mühendisleri Odası tarafından hazırlanan iş kazalarının faaliyet gruplarına göre dağılımı verilmiştir [1].

Risk değerlendirme çalışmalarına başlamadan önce işletmedeki yönetim kadrosu dahil olmak üzere tüm çalı- 
Tablo 1: İş kazalarının işyerinin faaliyet grubuna göre dağılımı [1]

\begin{tabular}{|c|c|c|}
\hline FAALIYET GRUBU & İş Kazası Sayısı & Yüzde (\%) \\
\hline Makine ve Teçhizat Hariç Fabrikasyon Metal Ürünleri İmalatı & 20.616 & 7,21 \\
\hline Bina İnşaat & 20.159 & 7,05 \\
\hline Özel İnşaat Faaliyetleri & 14.877 & 5,20 \\
\hline Gıda Ürünlerinin İmalatı & 14.351 & 5,02 \\
\hline Tekstil Ürünlerinin İmalatı & 13.446 & 4,70 \\
\hline Ana Metal Sanayii & 13.081 & 4,57 \\
\hline Yiyecek ve İçecek Hizmetleri Faaliyetleri & 12.626 & 4,41 \\
\hline Diğer Metalik Olmayan Mineral Ürünlerin İmalat & 11.721 & 4,10 \\
\hline Binalar ve Çevre Düzenlemesi Faaliyetleri & 11.631 & 4,07 \\
\hline Perakende Ticaret (Motorlu Kara Taşıtları ve Motosikletler Hariç) & 9.759 & 3,41 \\
\hline Motorlu Kara Taşıtları Treyler (Römorkör) ve Yarı Treyler (Yarı Römorkör) İmalatı & 9.533 & 3,33 \\
\hline Bina Dışı Yapıların İnşaatı & 9.516 & 3,33 \\
\hline Taşımacılık İçin Depolama ve Destekleyici Faaliyetler & 9.496 & 3,32 \\
\hline Kauçuk ve Plastik Ürünlerin İmalatı & 9.258 & 3,24 \\
\hline Kömür ve Linyit Çıkartılması & 8.274 & 2,89 \\
\hline Kara Taşımacılığı ve Boru Hattı Taşımacılığı & 7.246 & 2,53 \\
\hline Elektrikli Teçhizat İmalatı & 6.315 & 2,21 \\
\hline Başka Yerde Sınıflandırılmamış Makine ve Ekipman İmalatı & 6.276 & 2,19 \\
\hline Konaklama & 5.397 & 1,89 \\
\hline Mobilya İmalat & 5.013 & 1,75 \\
\hline Toptan Ticaret (Motorlu Kara Taşıtları ve Motosikletler Hariç) & 4.835 & 1,69 \\
\hline Eğitim & 4.744 & 1,66 \\
\hline Attğın Toplamanması Islahı ve Bertarafi Faaliyetleri Maddelerin Geri Kazanımı & 4.483 & 1,57 \\
\hline İnsan Sağlığı Hizmetleri & 4.460 & 1,56 \\
\hline Makine ve Ekipmanların Kurulumu ve Onarımı & 4.277 & 1,50 \\
\hline Diğer Faaliyet Grupları* & 44.678 & 15,62 \\
\hline Toplam & 286.068 & 100 \\
\hline
\end{tabular}

şanlara yönelik bilgilendirme toplantıları yapılması, konuyla ilgili eğitimler verilmesi gerekir. Değerlendirme aşamasında tehlikeler ve risklerin tanımının doğru yapılması ve bu tehlikelerin doğru veriler ile ilişkilendirilmesi gerekmektedir. Kalitatif, kantitatif ve karma olmak üzere yaklaşı 150 adet risk değerlendirme yöntemi bulunmaktadır. Ancak her yöntem aktif olarak kullanılmamakla birlikte, her sektörde aynı yöntemi kullanmak uygun değildir.

Çalışmada, yukarıda belirtilen amaçlara uygun olarak Kdz. Ereğli'de orta ölçekli bir metal imalat firmasında, 5x5 Matris (L Tipi Matris) ve Fine-Kinney yöntemleri kullanılarak risk değerlendirmesi yapılmıştır. Uygulama ve değerlendirme kriterleri farklı olan bu iki yöntemin karşılaştırılarak, işyeri için en kesin sonuçlara ulaşılmaya çalsşılmıştır.
Kullanılan yöntemlerin daha iyi anlaşılması adına aşağıdaki kavramların bilinmesinde fayda vardır.

Risk değerlendirmesi: İşyerinde var olan ya da dışarıdan gelebilecek tehlikelerin belirlenmesi, bu tehlikelerin riske dönüşmesine yol açan faktörler ile tehlikelerden kaynaklanan risklerin analiz edilerek derecelendirilmesi ve kontrol tedbirlerinin kararlaşıııılması amacıyla yapılması gerekli çalışmalardır [6].

Risk: Tehlikeden kaynaklanacak kayıp, yaralanma ya da başka zararlı sonuç meydana gelme ihtimalidir [6].

Tehlike: İşyerinde var olan ya da dışarıdan gelebilecek, çalışanı veya işyerini etkileyebilecek zarar veya hasar verme potansiyelidir [6]. 
Olasılık: Bir şeyin olabilmesi durumudur [8].

Frekans: Ele alınan tehlike ve riskin meydana gelme sıklığıdır.

Şiddet: Olası riskin gerçekleşmesi durumunda insan, ekipman ve çevre üzerinde tahmin edilen etkisidir.

\section{MATERYAL VE YÖNTEM}

Kdz. Ereğli'de örnek bir metal imalat atölyesindeki çalışma ortam koşulları, makine, insan ve çevre faktörleri bir arada değerlendirilerek elde edilen verilerle genel risk değerlendirme raporu hazırlanmıştır.

Çalışmanın yapıldığı firmada öncelikle risk değerlendirmesi için atölyedeki mevcut tehlikeleri belirlemek adına işyeri birimleri ayrıntılı bir şekilde incelenmiştir. İşyerinde döküm, şekillendirme, kaynak, talaşılı imalat, taşlama, parlatma, zımparalama, yüzey işleme ve yüzey kaplama birimleri faaliyet göstermektedir. Bir metal atölyesinde karşılaşılabilecek başlıca risk etmenleri genel başlığı altında belirtilmiş olup, kaynak ve montaj işleri, el aletleri kullanımı, elektrik işleri, vinç kullanımı, merdiven kullanımı, forklift, manlift, caraskal, torna ve CNC makinalarının kullanımı faaliyet alanlarından oluşmak üzere yaklaşık 140 adet risk belirlenmiştir. Çalışma alanında özellikle kaynak işlemleri ve kompleks el aletlerinin kullanılmasında, oldukça ciddi sonuçlanan büyük riskler ve tehlikeler meydana gelmektedir.

Çalışmada, ilk olarak iş güvenliğinde en çok kullanılan yöntemlerin başında gelen ve uygulaması basit ve anlaşılır olan 5x5 Matris yöntemi kullanılmıştır. Sebep-sonuç ilişkisi ile işyerindeki riskler belirlenip, sonuçlarına göre kontrol önlemleri önerilmiştir. 5x5 Matris yönteminde, uygulayan kişinin fikir ve tercihlerine göre değişen değerlendirme sonuçları elde edilmekte olup, objektif sonuçlar vermemesi dezavantaj olmaktadır. Bu aşamada bilgi düzeyi ve tecrübe bu risk değerlendirmesinin niteliği üzerinde etkili olmaktadır. Verilen olasılık ve şiddet değerlerine bağlı olarak ortaya çıkan risk düzeyi kabul edilebilir risk olarak çıksa dahi, tehlikenin gerçekleşmesi durumunda şiddetinin yüksek oluşundan dolayı ciddi sonuçlar doğurabilmektedir. Bu yöntemin risk sonucunu oluşturmak için iki değişkene sahip olması dezavantaj olarak görüldüğünden olasılık ve şiddete ilave olarak bir başka parametreye sahip olan FineKinney yöntemi uygulamaya dahil edilmiştir. Bu yöntem ile frekans değeri de kullanılmakta olup, daha ayrıntılı bir değerlendirme imkanı bulunmuştur.

\section{A. $5 \times 5$ Matris Yöntemi}

Risk değerlendirmede matris yöntemi en sık kullanılan yaklaşımlardan biri olup, ABD Askeri standardı MIL_STD_882-D olarak da bilinen sistem güvenlik program gereksinimi karşılamak maksadıyla geliştirilmiştir. 5x5 Matris yöntemi (L Tipi Matris) özellikle sebep-sonuç ilişkilerinin değerlendirilmesinde kullanılmaktadır. Yöntem tek başına risk analizi yapmak durumunda olan analistler için idealdir, ancak değişik prosesler içeren veya birbirinden çok farklı akım şemasına sahip işlerin hepsi için tek başına yeterli değildir. Bu tarz durumlarda acil önlem gerektiren tehlikelerin tespit edilmesi için kullanılmalıdır. Bu yöntem ile öncelikle bir olayın gerçekleşme olasılı̆̆ı ile gerçekleşmesi takdirde sonucunun oluşturacağı şiddetinin derecelendirilmesi ve ölçümü yapılmaktadır [9].

Risk skoru olasılık ve şiddet değerlerinin çarpımından elde edilmektedir ve risk derecesine göre büyükten başlayarak gerekli önlemler alınmaktadır.

$$
\text { Risk Skoru }=\text { Olasilık } \times \text { Şiddet }
$$

Aşağıdaki tablolarda $5 \times 5$ matris yöntemine göre bir olayın gerçekleşmesi durumunda olasılık, şiddet, risk değerleri ve bu değerlerin anlamları verilmiştir [10]. 
Tablo 2: 5x5 Matris Yönteminde Bir Olayın Gerçekleşme Olasılığı Değerleri

\begin{tabular}{cc}
\hline OLASILIK & $\begin{array}{c}\text { ORTAYA ÇIKMA OLASILIĞı içiN } \\
\text { DERECELENDIRME BASAMAKLARI }\end{array}$ \\
\hline ÇOK KÜÇÜK & Hemen hemen hiç \\
KÜÇÜK & Çok az (yılda bir kez), sadece anormal durumlarda \\
ORTA & Az (yılda birkaç kez) \\
YÜKSEK & Sıklıkla (ayda bir) \\
ÇOK YÜKSEK & Çok sıklıkla (haftada bir, her gün), normal çalışma \\
şartlarında
\end{tabular}

Tablo 3: 5x5 Matris Yönteminde Bir Olayın Gerçekleştiği Takdirde Şiddet Değerleri

\begin{tabular}{|c|c|}
\hline ŞIDDET & DERECELENDIRME \\
\hline ÇOK HAFiF & İş saati kaybı yok, ilk yardım gerektiren \\
\hline HAFIF & $\begin{array}{c}\text { İş günü kaybı yok, kalıcı etkisi olmayan, ayakta tedavi } \\
\text { ilk yardım gerektiren }\end{array}$ \\
\hline ORTA & Hafif yaralanma, yatarak tedavi gerektirir \\
\hline CIDDi & Ciddi yaralanma, uzun süreli tedavi, meslek hastalığı \\
\hline ÇOK CIDDi & Ölüm, sürekli iş görmezlik \\
\hline
\end{tabular}

Tablo 4: 5x5 Matris Yönteminde Risk Düzeyi Tablosu

\begin{tabular}{|c|c|c|c|c|c|}
\cline { 2 - 6 } \multicolumn{1}{c|}{} & \multicolumn{5}{c|}{ ŞiDDET } \\
\hline OLASILIK & $\begin{array}{c}\text { Çok Hafif } \\
1\end{array}$ & $\begin{array}{c}\text { Hafif } \\
2\end{array}$ & $\begin{array}{c}\text { Orta } \\
3\end{array}$ & $\begin{array}{c}\text { Ciddi } \\
4\end{array}$ & $\begin{array}{c}\text { Çok } \\
\text { Ciddi } \\
5\end{array}$ \\
\hline $\begin{array}{c}1 \text { (Çok } \\
\text { Küçük) }\end{array}$ & $\begin{array}{c}\text { Önemsiz } \\
1\end{array}$ & $\begin{array}{c}\text { Düşük } \\
2\end{array}$ & $\begin{array}{c}\text { Düşük } \\
3\end{array}$ & $\begin{array}{c}\text { Düşük } \\
4\end{array}$ & $\begin{array}{c}\text { Düşük } \\
5\end{array}$ \\
\hline $\begin{array}{c}\text { (Küçük) } \\
\text { 3 (Orta) }\end{array}$ & $\begin{array}{c}\text { Düşük } \\
\mathbf{2}\end{array}$ & $\begin{array}{c}\text { Düşük } \\
4\end{array}$ & $\begin{array}{c}\text { Düşük } \\
6\end{array}$ & $\begin{array}{c}\text { Orta } \\
8\end{array}$ & $\begin{array}{c}\text { Orta } \\
10\end{array}$ \\
\hline $\begin{array}{c}\text { Düşük } \\
6\end{array}$ & $\begin{array}{c}\text { Orta } \\
9\end{array}$ & $\begin{array}{c}\text { Orta } \\
12\end{array}$ & $\begin{array}{c}\text { Yüksek } \\
15\end{array}$ \\
\hline $\begin{array}{c}\text { (Yüksek) } \\
\text { Yüksek) }\end{array}$ & $\begin{array}{c}\text { Düşük } \\
\mathbf{5}\end{array}$ & $\begin{array}{c}\text { Orta } \\
\mathbf{8}\end{array}$ & $\begin{array}{c}\text { Orta } \\
12\end{array}$ & $\begin{array}{c}\text { Yüksek } \\
16\end{array}$ & $\begin{array}{c}\text { Yüksek } \\
20\end{array}$ \\
\hline & Düš̈k & $\begin{array}{c}\text { Orta } \\
10\end{array}$ & $\begin{array}{c}\text { Yüksek } \\
15\end{array}$ & $\begin{array}{c}\text { Yüksek } \\
20\end{array}$ & $\begin{array}{c}\text { Kabul } \\
\text { Edilemez } \\
25\end{array}$ \\
\hline
\end{tabular}

Tablo 5: 5x5 Matris Yönteminde Risk Değerlendirme Sonucu

\begin{tabular}{|c|c|}
\hline Risk Değeri & Risk Değerlendirme Sonucu (Eylem) \\
\hline $\begin{array}{l}\text { Kabul Edile- } \\
\text { mez Riskler } \\
(25)\end{array}$ & $\begin{array}{l}\text { Belirlenen risk kabul edilebilir seviyeye düşürülün- } \\
\text { ceye kadar iş başlatılmamalı eğer devam eden bir } \\
\text { faaliyet varsa derhal durdurulmalıdır. Alınan önlem- } \\
\text { lere rağmen riski düşürmek mümkün olmuyorsa, } \\
\text { faaliyet engellenmelidir. }\end{array}$ \\
\hline $\begin{array}{l}\text { Önemli } \\
\text { (Yüksek) } \\
\text { Riskler } \\
(15,16,20)\end{array}$ & $\begin{array}{l}\text { Belirlenen risk azalıncaya kadar iş başlatılmamalı } \\
\text { eğer devam eden bir faaliyet varsa derhal durdurul- } \\
\text { malıdır. Risk işin devam etmesi ile ilgili ise acil ön- } \\
\text { lem alınmalı ve bu önlemler sonucunda faaliyetin } \\
\text { devamına karar verilmelidir. }\end{array}$ \\
\hline $\begin{array}{l}\text { Orta } \\
\text { Düzeydeki } \\
\text { Riskler } \\
(8,9,10,12)\end{array}$ & $\begin{array}{l}\text { Belirlenen riskleri düşürmek için faaliyetler başlatıl- } \\
\text { malıdır. Risk azaltma önlemleri zaman alabilmekte- } \\
\text { dir. }\end{array}$ \\
\hline $\begin{array}{l}\text { Kabul Edilebilir } \\
\text { (Düşük) Riskler } \\
(2,3,4,5,6)\end{array}$ & $\begin{array}{l}\text { Belirlenen riskleri ortadan kaldırmak için ilave kont- } \\
\text { rol işlemlerine ihtiyaç olmayabilir; ancak mevcut } \\
\text { kontroller sürdürülmeli ve bu kontrollerin sürdürül- } \\
\text { düğü denetlenmelidir. }\end{array}$ \\
\hline $\begin{array}{l}\text { Önemsiz } \\
\text { Riskler (1) }\end{array}$ & $\begin{array}{l}\text { Belirlenen riskleri ortadan kaldırmak için kontrol } \\
\text { faaliyetlerini planlamaya ve gerçekleştirilecek faali- } \\
\text { yetlerin kayıtlarını saklamaya gerek olmayabilmek- } \\
\text { tedir. }\end{array}$ \\
\hline
\end{tabular}

\section{B. Fine-Kinney Yöntemi}

Fine-Kinney risk değerlendirme yöntemi Fine tarafindan "Tehlikelerin Kontrolü İçin Matematiksel Değerlendirme” adı altında 1971 yılında Kaliforniya Donanma Silah Merkezi için geliştirilmiştir [11]. Kinney ve Wiruth tarafindan 1976'da revize edilerek "Practical Risk Analysis for Safety Management” adı altında yayınlanmıştır. Günümüzde Fine-Kinney yöntemi olarak bilinmektedir [12].

Fine-Kinney risk analizi yöntemi, iş sağlığı ve güvenliği risk değerlendirmesinde sık olarak kullanılan yöntemlerden biridir. İşletmenin geçmiş verilerini kullanan kalitatif (nitel) bir yöntem olup, sadece kaza olma olasılığı ve şiddetini değil risk altındaki kişilerin tehlikeye maruz kalma sıklığını da dikkate almaktadır. Bundan dolayı, 5x5 Matris yöntemine göre daha güvenilir ve daha doğru bir analiz yapılması imkanı sağlamaktadır [13].

Fine-Kinney risk değerlendirme yöntemi; 
$R=$ Olasillk $x$ Frekans $x$ Şiddet olarak hesaplanmakta olup, (R) bu üç verinin çarpımından oluşan risk derecesidir.

Kinney ve Wiruth, yöntemin altındaki temel düşünceyi aşağıdaki şekilde ifade etmişlerdir:

- Hayatımızdaki tehlikeler tamamen önlenebilir değildir, tehlikelere karşı bütün riskleri ortadan kaldırmak mümkün değildir.

- Dikkatli düşünerek ve çaba sarf ederek günlük hayattaki riskler kabul edilebilir seviyeye düşürülebilir.

- Sınırlı zaman ve emek kaynakları, riskleri tamamen ortadan kaldırmak yerine riski azaltmak ve maksimum fayda sağlamak için kullanılmalıdır [14].

Aşağıdaki tablolarda Fine-Kinney yönteminin olasılık, frekans ve şiddet değerleri ile bu değerlerin anlamları ve bu değerlerin çarpımından oluşan risk değerlendirme sonucu yer almaktadır [12].

Olasılık, şiddet, frekans faktörlerinin çarpımından oluşan risk puanı grafiksel olarak hesaplanır. Grafiksel olarak hesaplanan ölçekler doğada logaritmiktir ve şiddet ve frekans faktörleri olasılık faktörünün logaritması ile orantılıdır [14].

Tablo 6: Fine-Kinney Yöntemi Olasılık Değerleri

\begin{tabular}{cc}
\hline Olasılık Değeri & Anlamı \\
\hline 0,2 & Pratik Olarak Anlamsız \\
0,5 & Zayıf Olasılık \\
1 & Oldukça Düşük Olasılık \\
3 & Nadir Fakat Olabilir \\
6 & Kuvvetle Muhtemel \\
10 & Çok Kuvvetli Olasılık \\
\hline
\end{tabular}

Tablo 7: Fine-Kinney Yöntemi Frekans Değerleri

\begin{tabular}{cc}
\hline Frekans Değeri & Anlamı \\
\hline 0,5 & Çok Nadir (yılda bir ya da daha az) \\
1 & Oldukça Nadir (yılda bir ya da birkaç kez) \\
2 & Nadir (ayda bir ya da birkaç kez) \\
3 & Ara Sıra (haftada bir ya da birkaç kez) \\
6 & Sıklıkla (günde bir ya da birkaç kez) \\
10 & Sürekli (sürekli ya da saatte birden fazla ) \\
\hline
\end{tabular}

Tablo 8: Fine-Kinney Yöntemi Şiddet Değerleri

\begin{tabular}{|c|c|}
\hline Şiddet Değeri & Anlamı \\
\hline 1 & Dikkate Alınmalı (hafif, zararsız veya önemsiz) \\
\hline 3 & $\begin{array}{l}\text { Önemli (düşük iş kaybı, küçük hasar, ilk yardım ge- } \\
\text { rektirir) }\end{array}$ \\
\hline 7 & Ciddi (önemli hasar, dış tedavi, iş gücü kaybı) \\
\hline 15 & Çok Ciddi (sakatlık, uzuv kaybı, çevresel etki) \\
\hline 40 & Çok Kötü (ölüm, tam maluliyet, ağır çevre etkisi) \\
\hline 100 & Felaket (birden çok ölüm, önemli çevre felaketi) \\
\hline \multicolumn{2}{|r|}{$\begin{array}{c}\text { Tablo 9: Fine-Kinney Yöntemi Risk } \\
\text { Değerlendirme Sonucu }\end{array}$} \\
\hline Risk Değeri & Risk Değerlendirme Sonucu \\
\hline $\mathrm{R}<20$ & Kabul Edilebilir Risk (acil tedbir gerekmeyebilir) \\
\hline $20<R<70$ & Kesin Risk (eylem planına alınmalı) \\
\hline $70<R<200$ & $\begin{array}{l}\text { Önemli Risk (dikkate alınmalı ve yıllık eylem planına } \\
\text { alınmalı) }\end{array}$ \\
\hline $200<R<400$ & Yüksek Risk (kısa vadeli eylem planına alınmalı) \\
\hline $\mathrm{R}>400$ & $\begin{array}{l}\text { Çok Yüksek (çalışmaya ara verilerek derhal tedbir } \\
\text { alınmalı) }\end{array}$ \\
\hline
\end{tabular}

\section{B. Yöntemlerin karşılaştırılması}

Araştırmada işyerindeki tüm birimler incelenerek birçok faaliyet alanındaki riskler belirlenmiştir. Ancak atölyede kullanım sıklığı ve kullanan kişi sayısının fazlalığı açısından en riskli iş kollarının başında gelen, kaynak işlerine bağlı riskler risk değerlendirme çalışmasının önemli kısmını oluşturmaktadır. Kaynak işleri başlığı alında ele alınan yaklaşık otuz (30) risk etmeni bulunmakta olup, yöntemlerin karşılaştırılması için "kaynak ışınları tehlikesi” ayrıntılı olarak incelenmiştir.

Her gün elektrik kaynağı kullanmakta olan bir çalışan günde birkaç defa kaynak ışınına maruz kalmaktadır. 5x5 Matris yöntemine göre, olasılık değeri 4, şiddet değeri ise göz rahatsızlıkları ve yaralanma riskleri sebebiyle 4 alınmıştır. Fine-Kinney yönteminde ise; olasllık değeri yüksek olduğundan 6 , şiddet değeri yaralanma olduğundan 15 , frekans değeri işin günde birden fazla yapılmasından dolayı 6 alınmıştır. 
Tablo 10: Kaynak Işınlarının Riski İçin 5x5 Matris Yöntemi

\begin{tabular}{|c|c|c|c|c|c|}
\hline YAPILAN IŞ/KATEGORI & TEHLIKE & RisK & $\begin{array}{c}\text { OLASI- } \\
\text { LIK }\end{array}$ & ŞiDDET & RiSK SEVIYESi \\
\hline KAYNAK IŞLERI & $\begin{array}{l}\text { KAYNAK IŞININA } \\
\text { MARUZ KALMA }\end{array}$ & GÖZ RAHATSIZLIKLARI & 4 & 4 & 16 \\
\hline
\end{tabular}

Tablo 11: Kaynak Işınlarının Riski İçin Fine-Kinney Yöntemi

\begin{tabular}{|c|c|c|c|c|c|c|}
\hline YAPILAN IŞ/KATEGORi & TEHLIKE & RisK & $\begin{array}{l}\text { OLASI- } \\
\text { LIK }\end{array}$ & $\begin{array}{l}\text { FRE- } \\
\text { KANS }\end{array}$ & ŞIDDET & RiSK SEVIYESi \\
\hline KAYNAK IŞLERI & $\begin{array}{l}\text { KAYNAK IŞININA } \\
\text { MARUZ KALMA }\end{array}$ & GÖZ RAHATSIZLIKLARI & 6 & 6 & 15 & 540 \\
\hline
\end{tabular}

Tablo 12: Kaynak Işınlarının Riski İçin İndirgenmiş 5x5 Matris Yöntemi

\begin{tabular}{ccccccc}
\hline $\begin{array}{c}\text { YAPILAN IŞ/ } \\
\text { KATEGORi }\end{array}$ & TEHLiKE & RISK & ALINACAK ÖNLEMLER & OLASILIK & şidDET & RiSK SEVIYESi \\
\hline \multirow{2}{*}{ KAYNAK IŞLERi } & $\begin{array}{c}\text { KAYNAK IŞININA } \\
\text { MARUZ KALMA }\end{array}$ & GÖZ RAHATSIZLIKLARI & $\begin{array}{c}\text { KAYNAK MASKESi } \\
\text { KULLANILMALI }\end{array}$ & 1 & 4 & 4 \\
\hline
\end{tabular}

Tablo 13: Kaynak Işınlarının Riski İçin İndirgenmiş Fine-Kinney Yöntemi

\begin{tabular}{|c|c|c|c|c|c|c|c|}
\hline YAPILAN IŞ/KATEGORi & TEHLIKE & RiSK & ALINACAK ÖNLEMLER & OLASILIK & FREKANS & ŞiDDET & RISK SEVIYESi \\
\hline KAYNAK IŞLERI & $\begin{array}{l}\text { KAYNAK IŞININA } \\
\text { MARUZ KALMA }\end{array}$ & GÖZ RAHATSIZLIKLARI & $\begin{array}{l}\text { KAYNAK MASKESI } \\
\text { KULLANILMALI }\end{array}$ & 0,5 & 6 & 15 & 45 \\
\hline
\end{tabular}

Verilen bu risk derecelerine bağlı olarak, kaynak ışınları tehlikesi, Tablo-10'da gösterildiği gibi, 5x5 Matris yöntemine göre risk derecesi 16 olduğundan "önemli", Tablo11'de gösterildiği gibi Fine-Kinney yöntemine göre risk derecesi 540 olduğundan "kabul edilemez" risk grubunda bulunmaktadır. Önleyici faaliyet olarak kişisel koruyucu donanımların kullanılması ile birlikte, 5x5 Matris yönteminde risk derecesi 4'e düşerek "kabul edilebilir" düzeye indirgenmiş olup (Tablo-12), Fine-Kinney yönteminde frekans değerinin değişmemesi sebebiyle risk derecesi 45 olduğundan "olası" risk grubunda yer almaktadır (Tablo13).

\section{BULGULAR VE TARTIŞMA}

Çalışmada metal imalat işletmesinde genel çalışma alanı, kaynak ve montaj işleri, elektrikli el aletleri kullanımı, yüksekte çalısma, vinç, forklift, manlift, caraskal kullanımı, torna ve CNC tezgahlarının bulunduğu bölümlerde oluşan riskler değerlendirilmiştir.
Matris yöntemine göre kaynak işleri alanında yapılan risk derecelendirilmesi sonucu, elde edilen risk skorlarına göre, 17 adet orta düzeyde ve 10 adet önemli risklerin olduğu saptanmıştır. Alınması gereken önlemler risk değerlendirme raporunda aynı satır içerisinde belirtilmiş ve risk derecelerinin tümünün, 2-6 puan aralığında kabul edilebilir seviyeye indirgenebildiği görülmüştür.

Uygulanan bir diğer yöntem olan Fine-Kinney yöntemine göre ise, toplam 27 adet risk maddesinin, 1'i olası, 1'i önemli ve 25 'i kabul edilemez risk olarak belirlenmişsir. Ancak, alınan önlemlere rağmen elde edilen sonuç derecelerine göre sadece 4 adet risk kabul edilebilir seviyeye indirgenebilmiştir. Hala önemli risklerin var olduğu ve etkin bir iş güvenliği ile risklerin takibinin yapılması gerektiği görülmektedir.

Yöntemlerin karşılaştırılması amacıyla ele alınan örnek tehlike maddesinde de analiz edildiği üzere, atölyede yapılan risk değerlendirmesi sonucu elde edilen risk skorlarına göre, Fine-Kinney ve 5x5 Matris yöntemleri arasında çıkan 
sonuç farklılıklarının nedeninin, Fine-Kinney yönteminde kullanılan frekans parametresi olduğu görülmüştür. Olasılık ve şiddet parametrelerine atanan değer aralıklarının da farklı olması sebebiyle Fine-Kinney yönteminde daha hassas sonuçlar elde edilmesi de çalışmada yer alan önemli bulgulardandır.

\section{SONUÇ}

Son yıllarda ülkemizde, iş sağlığı ve güvenliği çalışmalarının daha aktif hale gelmesiyle birlikte, iş kazaları ve kazalar sonucunda oluşan iş görmezlik, kayıp iş günleri gibi olumsuz sonuçların önlenmesi konusunda önemli adımlar atılmıştır. İşyerinde tehlikelerin önlenmesi, risklerin öngörülmesi, sistemli bir şekilde değerlendirilerek tamamen ortadan kaldırılabilmesi veya zararlarının mümkün mertebe en aza indirilmesi gerekmektedir.

Çalışmada yukarıda belirtilen amaca uygun olarak Kdz. Ereğli'de metal sektöründe faaliyet gösteren orta ölçekli bir firmanın atölyesinde risk değerlendirmesi yapılmış olup, 5x5 Matris yöntemi ile birlikte Fine-Kinney yöntemi kullanılmıştır. Yöntemler, kaynak, elektrikli el aletleri, iş makinaları başta olmak üzere atölyedeki tüm faaliyet alanlarında uygulanmıştır.

Analizler göstermiştir ki, 5x5 Matris yöntemi sonucunda 10 adet ciddi düzeyde, 17 adet orta seviyede olmak üzere toplam 27 risk tespit edilmiş olup, risk tablosu ve alınacak kısa kontrol ve önlem faaliyetleri belirlenmiştir. (Ek-1) Alınan önlemler sonucunda 5x5 Matris yönteminde riskler \%100 oranında kabul edilebilir seviyeye indirgenmiştir. Fine-Kinney yöntemine göre ise toplam risklerin, 1'i olası, 1’i önemli, 25'i kabul edilemez düzeyde çımıştır ve tüm önlemlere rağmen riskler sadece \%14 oranında kabul edilebilir düzeye indirgendiği görülmüştür. (Ek-2) Elde edilen verilere göre, Fine -Kinney yönteminin daha hassas sonuçlar verdiği tespit edilmiştir.
Yapılan risk değerlendirmesi uygulamasında işyerinde belirlenen tehlikeler, neden olabileceği riskler ile ilgili derecelendirme tabloları uygulama eklerinde verilmiş olup, elde edilen sonuçlar ve riskler için alınması gereken önlemler tabloların devamında belirtilmiştir. Düzeltici-önleyici faaliyetlerin uygulanmasını sağlayacak verilerin kayıt alına alınması, sonuçlarının düzenli bir şekilde takibinin yapılmasını sağlamak gerekmektedir.

Çalışmada; işyerinde kimlerin ne derecede risk altında olduğu belirlenerek, risk kontrolü için yapılması gerekenler öncelik sırasına koyulmuş, önlem faaliyetlerinde ve uygun risk değerlendirme yöntemi seçimi konusunda işyerindeki iş güvenliği çalışmalarına katkı sağlanmıştır. Risklerin olumsuz etkileri azaltmak ve denetleyebilmek adına kanun ve yönetmelikler ışığında gereklilikleri yerine getirmek iş kazaları ve meslek hastalıklarını azaltacaktır.

\section{KAYNAKLAR}

[1] Makine Mühendisleri Oda Raporu, İşçi Sağlığı ve İş Güvenliği, Ankara, (2018), Yayın No: MMO/689 www.mmo.org.tr/sites/default//files/ gonderi_dosya_ekleri/isgraporu2018.pdf

[2] Özgür, M., 2013. Metal Sektöründe Risk Analizi Uygulaması, İş Müfettişliği Yardımcılığı Etüdü, 111 s.

[3] European Comission, Brussel . (1996). Health and Safety, Guidance on Risk Assessment at Work. https://osha.europa.eu/en/topics/riskassessment/ guidance.pdf

[4] Akpınar, T., ÇAKMAKKAYA, B. Y. (2014), İş Sağlığı ve Güvenliği Açısından İşverenlerin Risk Değerlendirme Yükümlülüğü. Çalışma ve Toplum, 40:273-304.

[5] T.C. Cumhurbaşkanlığı Mevzuat Bilgi Sistemi, 6331 Sayılı İş Sağlığı ve Güvenliği Kanunu. Erişim Tarihi: 28.04.20, https://www.mevzuat.gov.tr/mevzuat? MevzuatNo=6331\&MevzuatTur=1\&MevzuatTertip=5

[6] T.C. Cumhurbaşkanlığı Mevzuat Bilgi Sistemi, İş Sağlığı ve Güvenliği Risk Değerlendirmesi Yönetmeliği. Erişim Tarihi: 28.04.2020, https:// 
www.mevzuat.gov.tr/mevzuat?

Mev-

zuatNo=16925\&MevzuatTur=7\&MevzuatTertip=5

[7] Balçı, M., (2014). Metal Sektöründe İş Güvenliği. Bitirme Projesi, Yeni Yüzyıl Üniversitesi, 42s.

[8] T.C. Atatürk Kültür, Dil ve Tarih Yüksek Kurumu, Erişim Tarihi:18.05.20, www.tdk.gov.tr

[9] Özkılıç, Ö. 2005, Risk Değerlendirmesi, İș Müfettişleri Dergisi, 16-21 www.onderakademi.com/blog/isgdergi-makaleler/risk-analizi.pdf

[10] Özkılıç, Ö., (2005). İş Sağlığı ve Güvenliği, Yönetim Sistemleri ve Risk Değerlendirme Metodolojileri, Türkiye İşveren Sendikaları Konfederasyonu, Yayın No:46, Ankara

[11] Fine,W., (1971). Mathematical Evaluations For Comtrolling Hazards, Maryland:Naval Ordnance Laboratory White OAK, 4:157-166

[12] Erzurumluoğlu, K., Köksal, K. N.,Gerek, İ. H., (2016). İnşaat Sektöründe Fine-Kinney Metodu Kullanılarak Risk Analizi Yapılması, http:// www.imo.org.tr/resimler/ekutuphane/ pdf/17603_39_52.pdf

[13] Güven, B. (2018). Bütünleşik Bulanık Analitik Hiyerarşi Prosesi ve Bulanık Vikor Yöntemleri ile FineKinney Risk Değerlendirme Metodu Uygulaması:Silah Endüstrisinde Örnek Çalışma

[14] Kinney, G. F., Wiruth, A. (1976). Practical Risk Analysis for Safety Management, Naval Weapons Center, 5865 
Ek 1:

\begin{tabular}{|c|c|c|c|c|c|c|c|c|c|c|}
\hline $\begin{array}{l}\text { SIRA } \\
\text { NO }\end{array}$ & \begin{tabular}{|c|} 
YAPILAN \\
iș/KATEGORi
\end{tabular} & TEHLiKE & Risk & OLASIUK & ȘiDDET & $\begin{array}{c}\text { Risk } \\
\text { SEViYESi }\end{array}$ & ALINACAKÖNLEMLER & OLASIUK & ŞIDDET & $\begin{array}{c}\text { RisK } \\
\text { SEVIYESI }\end{array}$ \\
\hline 1 & KAYNAK ISTLERI & $\begin{array}{c}\text { KAYNAK IŞiNi YAPAN ÇALIŞA NIN } \\
\text { BELGESININ OLMAMASI } \\
\end{array}$ & IŞ KAZASI & 3 & 4 & 12 & 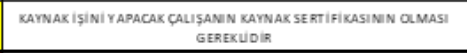 & 1 & 4 & 4 \\
\hline 2 & KAYNAK IȘLERI & KAYNAKIȘININA MARUZ KALMA & GÖZZRAHATSIZIIKLARI & 4 & 4 & 16 & KAYNAX MASKE SI KULANILMALI & 1 & 4 & 4 \\
\hline 3 & KAYNAK IŞLERI & AŞINMŞ HORTUM & PATLAMA, Iş KAZASI & 3 & 4 & 12 & 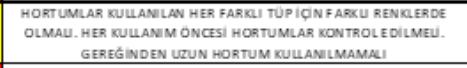 & 1 & 4 & 4 \\
\hline 4 & KAYNAK IŞLERI & $\begin{array}{l}\text { TÜPLER IÇiN TAŞ̦MA ARABALARININ } \\
\text { OLMAMASI } \\
\end{array}$ & $\begin{array}{c}\text { iNSAN GÜCÜ ILE TAŞINMASI } \\
\text { SONUCU DEVRILME }\end{array}$ & 4 & 5 & 20 & $\begin{array}{l}\text { KAYNAXX TUPLERI TASSIMA ARABALARI ILE TASSINMALIDIR.YE TERLI } \\
\text { SAYIDA TASTIMA ARABASI TEMIN EDILMEUDIR. }\end{array}$ & 1 & 5 & 5 \\
\hline 5 & KAYNAK IŞLERI & TÜPLERIN ELLERDE TAŞINMASI & DÜŞME VE PATLAMA & 4 & 5 & 20 & 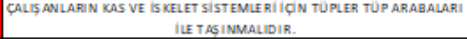 & 1 & 5 & 5 \\
\hline 6 & KAYNAK ISSLERI & TÜPLERIN DIK TUTULMAMASI & YARALANMA, PATLAMA & 3 & 4 & 12 & TÜPLER DIX VAZIYYTETE TUTULMAU, SAEITLENMEUDIR. & 1 & 4 & 4 \\
\hline 7 & KAYNAK IŞLERI & $\begin{array}{l}\text { KESIM VE KAYNAKISSLLERINDE YANGIN } \\
\text { SÖNDÜRÜCÜBULUNDURMAMA }\end{array}$ & $\begin{array}{l}\text { YANGINA MÜDAHELE } \\
\text { EDEMEME, IŞ KAZASI } \\
\end{array}$ & 3 & 4 & 12 & $\begin{array}{l}\text { ATE ȘU CALISTMALARIN HE PSINDE YAGIN SON D URÜCU } \\
\text { BUIUNDURULMAUDIR. }\end{array}$ & 1 & 4 & 4 \\
\hline 8 & KAYNAK IŞLERI & YANICI MA DDELERIN YAKININDA ÇALIŞMA & YANGIN VE PATLAMA & 4 & 5 & 20 & YANIC MALZZ MENIN OLDUGU ALANDA CALISIIMAMALIDIR. & 1 & 5 & 5 \\
\hline 9 & KAYNAK IŞLERI & $\begin{array}{l}\text { OKSI-ASETILEN TÜPLERIN BASINÇ } \\
\text { GÖSTERGELERININ BOZUKOLMASI }\end{array}$ & $\begin{array}{c}\text { YÜKSEK BASINÇU ELVERIŞSIZ } \\
\text { ORTAMDAÇAUŞMA }\end{array}$ & 3 & 4 & 12 & 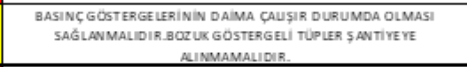 & 1 & 4 & 4 \\
\hline 10 & KAYNAK IŞLERI & TÜPLERIN AÇIKTA DEPOLANMASI & YANGIN VE PATLAMA & 4 & 5 & 20 & 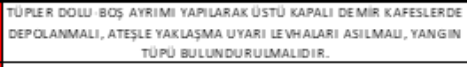 & 1 & 5 & 5 \\
\hline 11 & KAYNAK IȘLERI & KAYNAK GAZZARI & $\begin{array}{l}\text { GAZLARIN SOLUNMMASI } \\
\text { SONUCU ÇEŞITLI } \\
\text { HASTALIKLAR }\end{array}$ & 4 & 4 & 16 & $\begin{array}{l}\text { MASKE KULLANILMAU VE KAPAU ORTAMLAR ICQN ASPRARASTON SISTEMI } \\
\text { YAPILMALIDIR. }\end{array}$ & 1 & 4 & 4 \\
\hline 12 & KAYNAK IŞLERI & KAYNAK SIRASINDA OLUŞAN ÇAPAKLAR & $\begin{array}{l}\text { GÖZE ÇAPAK KAÇMASI } \\
\text { SONUCUYARALANMA }\end{array}$ & 4 & 4 & 16 & KORUYUCU IS GOZZUGÜ KULANILMALIDIR. & 1 & 4 & 4 \\
\hline 13 & KAYNAK IȘLERI & KESIMVE KAYNAK & $\begin{array}{c}\text { YANICI, YAKICIVE PATLAYICI } \\
\text { MALZEME BULUNMASI } \\
\end{array}$ & 3 & 4 & 12 & 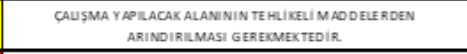 & 1 & 4 & 4 \\
\hline 14 & KAYNAK IȘLERI & $\begin{array}{l}\text { YAG̈LI EL VE ELDIVENLE OKSIJEN } \\
\text { TÜPLERININ KULLANILMASI }\end{array}$ & PATLAMA, YANGIN & 3 & 5 & 15 & 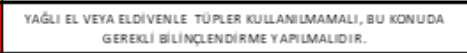 & 1 & 5 & 5 \\
\hline 15 & KAYNAK IŞLERI & $\begin{array}{l}\text { OKSI-ASETILEN TÜPLERIN GERI TEPME } \\
\text { VALFININ OLMAMASI }\end{array}$ & \begin{tabular}{|c|} 
ALEVIN TÜP IÇERISINE \\
GIRMESI SONUCU PATLAMA \\
\end{tabular} & 3 & 5 & 15 & TUPERE GERI TEPME VALFLERI TARIMALUIR. & 1 & 5 & 5 \\
\hline 16 & KAYNAK IȘLERI & $\begin{array}{l}\text { DEPOLAMA ALANLARININ Bi LINÇSiZ } \\
\text { KULLANIM }\end{array}$ & ELEKTRIK ÇARPMASI & 2 & 4 & 8 & TUPLER ILE YANGIN SCOOURUCULER AYNI ORTAMDA BULUNMAMAUDIR. & 1 & 4 & 4 \\
\hline 17 & KAYNAK IŞLERI & ELEKTROD KAYNAĞI AKIM ÜRETEÇLERI & ELEKTRIK ÇARPMASI & 3 & 4 & 12 & 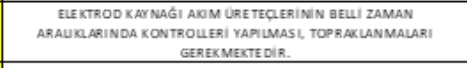 & 1 & 4 & 4 \\
\hline 18 & KAYNAK IȘLERI & TÜPLERIN VINÇ ILE TAŞINMASI & DÜŞME & 3 & 4 & 12 & TUUPLERIN TAŞINMA ARABALARI ILE TAŞINMASI GEREXMEKTEDIR. & 1 & 4 & 4 \\
\hline 19 & KAYNAK IŞLERI & TÜPLERIN SICAKTA BEKLETILMESI & PATLAMA VE YANGIN & 3 & 4 & 12 & 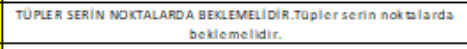 & 1 & 4 & 4 \\
\hline 20 & KAYNAK IȘLERI & $\begin{array}{l}\text { TÜPLERIN GÜNESS ISIINLARINA MARUZ } \\
\text { KALMAS| } \\
\end{array}$ & PATLAMA VE YANGIN & 3 & 4 & 12 & $\begin{array}{l}\text { TUPLLER GUNEES ISIINLARINDAN KORUNMAU, UYGUN YERLERDE } \\
\text { MUHAFAZA EDILMELIDIR. }\end{array}$ & 1 & 4 & 4 \\
\hline 21 & KAYNAK IŞLERI & TÜPLERIN BAĞLANMAMASI & DEVRILME, Iş KAZASI & 3 & 5 & 15 & 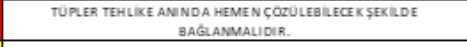 & 1 & 5 & 5 \\
\hline 22 & KAYNAK IȘLERI & ALEV GERI TEPME VENTILININ OLMAMASI & $\begin{array}{l}\text { TÜPLERDEN ALEVIN GERI } \\
\text { TEPMESI SONUCU } \\
\text { YARALANMALAR }\end{array}$ & 3 & 3 & 9 & ALEV GERI TE PME VENTILI KONULMAUDIR. & 1 & 3 & 3 \\
\hline 23 & KAYNAK IŞLERI & KESIMIŞ̧LERi & $\begin{array}{l}\text { GÖZ KORUYUCUSU } \\
\text { KULLANMAMA }\end{array}$ & 3 & 3 & 9 & KORUYUCU GOZZÜK KULLANLMAUDIR. & 1 & 3 & 3 \\
\hline 24 & KAYNAK IŞLERI & $\begin{array}{c}\begin{array}{c}\text { ELEKTROD KAYNAG̈I AKIMÜRETEÇLERININ } \\
\text { IZOLASYONU }\end{array} \\
\end{array}$ & $\begin{array}{l}\text { IZOLASYONUNUN } \\
\text { YAPILMAMASI }\end{array}$ & 3 & 3 & 9 & 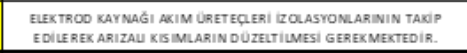 & 1 & 3 & 3 \\
\hline 25 & KAYNAK IŞLERI & MEMBRAN ISITIURKEN ALEV ALMASI & KAZA, YARALANMA & 3 & 4 & 12 & $\begin{array}{c}\text { IZOLASYON ISLLEMI SIRASINDA HAZIRDA YANGIN SOND URME CIHAZI } \\
\text { BUUWNDURLLMAUDIR. }\end{array}$ & 1 & 4 & 4 \\
\hline 26 & KAYNAK IȘLERI & I MEMBRAN & $\begin{array}{l}\text { ÇALIȘANLARIN ELLERINE } \\
\text { YAPIȘMASI }\end{array}$ & 3 & 4 & 12 & 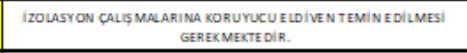 & 1 & 4 & 4 \\
\hline 27 & KAYNAK IŞLERI & KAYNAK KIVILCIMLARININ VARLGG| & YANIKLAR & 2 & 4 & 8 & $\begin{array}{l}\text { CAUSSANLARIN DERI ELDIVEN KULLANMALARI VE UZUN KOLU KIYAFET } \\
\text { GiVILMELDIR }\end{array}$ & 1 & 4 & 4 \\
\hline
\end{tabular}




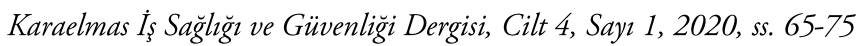

Ek 2:

\begin{tabular}{|c|c|c|c|c|c|c|c|c|c|c|c|c|}
\hline SIRA NO & \begin{tabular}{|c|} 
YAPILAN \\
IS/KATEGORI
\end{tabular} & TEHÜKE & Risk & OLASILIK & FREKANS & ȘDOET & $\begin{array}{c}\text { RisK } \\
\text { SEVIVESI }\end{array}$ & ALINACAK ONLEMLRR & oLASILIK & FREKANS & şiodet & \begin{tabular}{|c|c|c|} 
Risk \\
seviresi
\end{tabular} \\
\hline 1 & KAYNAK ISTLER & $\begin{array}{l}\text { KAYNAK IȘINI YAPAN CGALSSANIN } \\
\text { BEGESININ OLMAMASI }\end{array}$ & IŞ KAZASI & 3 & 2 & 15 & 90 & 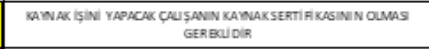 & 0,2 & 2 & 15 & 6 \\
\hline 2 & KAYNAK ISLILRI & KAYNAK LSIININA MARUZ KALMA & GOZRAHATSIZLIKLARI & 6 & 6 & 15 & 540 & KATNAG MASESSI KULANUMAU & 0,5 & 6 & 15 & 45 \\
\hline 3 & KAYNAK IșLRA & AŞIN MIŞ HORTUM & PATLAMA, IS KAZASI & 6 & 6 & 40 & 1440 & 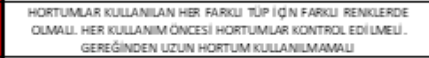 & 0,2 & 6 & 40 & 48 \\
\hline 4 & KAYNAK İLIER & $\begin{array}{l}\text { TUPLER IÇIN TASSMA ARABALARININ } \\
\text { OLMAMASI }\end{array}$ & $\begin{array}{c}\text { IN SAN GOCO ILE TASSIN MASI } \\
\text { SONUCU DEVRILME }\end{array}$ & 10 & 10 & 100 & 0000 & 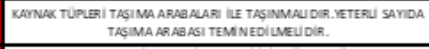 & 0,2 & 10 & $\$ 0$ & 80 \\
\hline 5 & KAYNAK IşLRRi & TUPIERIN EUIRROE TAŞINMASI & DOȘMEVE PATLAMA & 10 & 10 & 40 & 4000 & 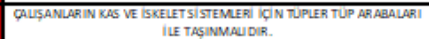 & 0,2 & 10 & 40 & 80 \\
\hline 6 & KAYNAK ISTLYOP & TUPLERIN DIK TUTULMAMASI & YARALANMA, PATLAMA & 3 & 3 & 7 & 63 & 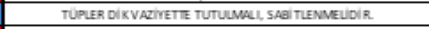 & 0.2 & 3 & 7 & 4,2 \\
\hline 7 & KAYNAK İ̧LRi & $\begin{array}{l}\text { KESIM VE KAYW AK ISSLERINDE YANGIN } \\
\text { SONDOROCO BULUNDURMAMA }\end{array}$ & $\begin{array}{l}\text { YANGINA MODAHELE } \\
\text { EDEMEME, IS KAZASI }\end{array}$ & 10 & 10 & 100 & 0000 & 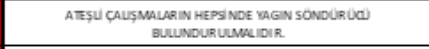 & 0.2 & 10 & 40 & 80 \\
\hline 8 & KAYNAK IȘ IERI & YANICI MADDELERIN YAKININ DA C,AUSSMA & YANGIN VE PATLAMA & 6 & 10 & 100 & 5000 & 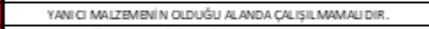 & 0,2 & 10 & 40 & 80 \\
\hline 9 & KAYNAK IşıRRi & $\begin{array}{l}\text { OKSI-ASETILEN TUPIFRIN BASINC } \\
\text { GOSTERGELERININ BOZUK OLMASI }\end{array}$ & $\begin{array}{c}\text { YOKSEK BASINÇU ELVERIŞSSIZ } \\
\text { ORTAMDA ÇAUŞMA }\end{array}$ & 6 & 10 & 100 & 6000 & 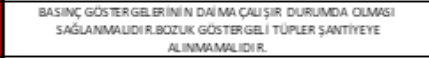 & 0,2 & 10 & $\infty$ & so \\
\hline 10 & KAYNAK IşLERi & TOPLLRIN AÇIKTA DEPOLAN MASI & YANGIN VE PATLAMA & 6 & 10 & 100 & 6000 & 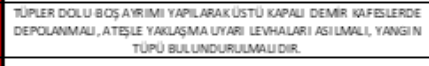 & 0,2 & 10 & $\$ 0$ & 80 \\
\hline 11 & KAYNAK IŞLERI & KAYNAK GAZLARI & $\begin{array}{l}\text { GAZLAAPIN SOLUN MASI } \\
\text { SONUCU ÇESITUI } \\
\text { HASTALIKLAR } \\
\end{array}$ & 10 & 10 & 40 & 4000 & 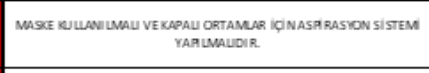 & 0.2 & 10 & $\$ 0$ & 80 \\
\hline 12 & KAYNAK IŞLRi| & KAYN AK SIRASINDA OLUŞAN ÇAPAKLAR & $\begin{array}{l}\text { GOZZ CAPAK KAC MASI } \\
\text { SONUCUYARALANMMA }\end{array}$ & 10 & 10 & 40 & 4000 & 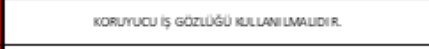 & 0,2 & 10 & $\$ 0$ & 80 \\
\hline 13 & KAYNAK IŞLERI & KESIM VE KAYNAK & $\begin{array}{c}\text { YANICI, YAKICIVE PATLAYICI } \\
\text { MALZEME BULUNMMASI } \\
\end{array}$ & 6 & 6 & 100 & 3600 & 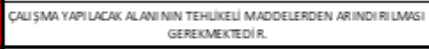 & 0,2 & 6 & 100 & 120 \\
\hline 14 & KAYNAK IŞLERI & $\begin{array}{l}\text { YAGU EL VEELDNENLE OKSIIUN } \\
\text { TOPLERININ KUUANIUMASI }\end{array}$ & PATLAMA, YANGIN & 6 & 6 & 100 & 3600 & 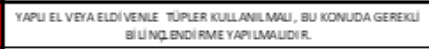 & 0,2 & 6 & 100 & 120 \\
\hline 15 & KAYNAK IșLERI & $\begin{array}{l}\text { OKSI-ASETILEN TOPLERIN GERI TEPME } \\
\text { VALFININ OUMAMASI }\end{array}$ & \begin{tabular}{|c|} 
ALEVIN TOP ICCERISINE \\
GIRMESI SON UCU PATLAMA \\
\end{tabular} & 6 & 6 & 100 & 3600 & TUPLERE GERI TEPME VALILRI TRAQUMAUDIR. & 0,2 & 6 & $\$ 0$ & 48 \\
\hline 16 & KAYNAK iș LRi & $\begin{array}{l}\text { DEPOLAMA ALANLARININ BIUNCSSIZ } \\
\text { KULLANIMI }\end{array}$ & ELEKTRIK ÇARPMASI & 3 & 10 & 100 & 3000 & 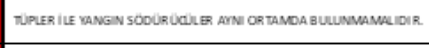 & 0,2 & 10 & 40 & 80 \\
\hline 17 & KAYNAK IȘLERi & ELEKTROD KAYNAGIAKIM ORETEÇLERI & ELEKTRIK ÇARPMASI & 6 & 10 & 40 & 2400 & 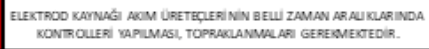 & 0,2 & 10 & $\$ 0$ & 80 \\
\hline 18 & KAYNAK İ̧ LERI & TUPLLRIN VINÇ ILE TAŞIN MASI & DOȘME & 3 & 6 & 40 & 720 & 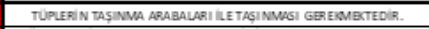 & 0,2 & 6 & 15 & 18 \\
\hline 19 & KAYNAK IşLRI & TUPLFRIN SICAKTA BEKLETIUMESI & PATLAMAVE YANGIN & 6 & 6 & 40 & 1440 & 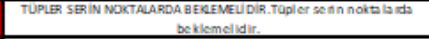 & 0,2 & 6 & 40 & 48 \\
\hline 20 & KAYNAK IșLERI & $\begin{array}{l}\text { TUPLERIN GONES ISINLLARINA MARUZ } \\
\text { KALMASI }\end{array}$ & PATLAMAVE YANGIN & 3 & 3 & 100 & 900 & 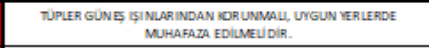 & 0,2 & 3 & 100 & 60 \\
\hline 21 & K.AYNAK İ̧ LPRi & TOPLERIN BAGLANMMAMASI & DEVRILME, IŞ KAZASI & 3 & 3 & 100 & 900 & 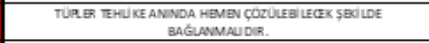 & 0,2 & 3 & 100 & 60 \\
\hline 22 & KAYNAK IŞLRRi & ALEV GERI TEPME VENTILININ OLMAMASI & $\begin{array}{l}\text { TUPLERDEN ALLVIN GERI } \\
\text { TEPMESI SO NUCU } \\
\text { YARALAN MALAR } \\
\end{array}$ & 6 & 10 & 15 & 900 & ALEV GERI TEPME VENTIU YONULMQU DIR. & 0,2 & 10 & 15 & 30 \\
\hline 23 & KAYNAK ISTLRI & KESIMIȘLERI & $\begin{array}{l}\text { GOZ KORUYYCUSU } \\
\text { KUUANMAMA }\end{array}$ & 6 & 6 & 15 & 540 & 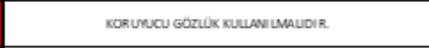 & 0,2 & 6 & 15 & 18 \\
\hline 24 & KAYNAK ISTLERI & $\begin{array}{l}\text { ELEKTROD KAYN AGGI AKIM ORETECCLLERININ } \\
\text { IZOLASYONU }\end{array}$ & $\begin{array}{l}\text { IZOLASYONUNUN } \\
\text { YAPILMAMASI }\end{array}$ & 6 & 3 & 40 & 720 & 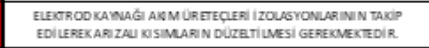 & 0,2 & 3 & $\$ 0$ & 24 \\
\hline 25 & KAYNAK IșLER & MEMERAN ISTTILRKEN ALEV ALMASI & KAZA, YARALANMA & 10 & 10 & 40 & 4000 & 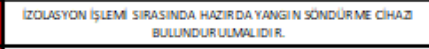 & 0,2 & 10 & $\$ 0$ & 80 \\
\hline 26 & KAYNA & ISTILAN MEMERAN & $\begin{array}{l}\text { ÇALISANLARIN EUERINE } \\
\text { YAPISTMASI }\end{array}$ & 10 & 10 & 40 & 4000 & 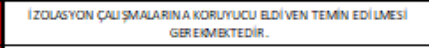 & 0.2 & 10 & $\$ 0$ & so \\
\hline 27 & KaYNAK IșLeri & KAYNAK KNILCIMLARININ VARUGI & YANIKLAR & 10 & 10 & 40 & $\infty$ & 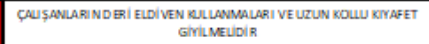 & 0.2 & 10 & $\$ 0$ & 80 \\
\hline
\end{tabular}

